\title{
Quality of life 4 years after complex heart surgery in infancy
}

\author{
Gonzalo Garcia Guerra, MD, ${ }^{\mathrm{a}}$ Charlene M. T. Robertson, MD, ${ }^{\mathrm{a}, \mathrm{b}}$ Gwen Y. Alton, MN, ${ }^{\mathrm{a}}$ Ari R. Joffe, MD, ${ }^{\mathrm{a}}$ \\ Irina A. Dinu, PhD ${ }^{\mathrm{b}, \mathrm{c}}$ David Nicholas, ${ }^{\mathrm{d}}$ David B. Ross, MD, ${ }^{\mathrm{e}}$ Ivan M. Rebeyka, MD,,${ }^{\mathrm{a}, \mathrm{e}}$ and the Western \\ Canadian Complex Pediatric Therapies Follow-up Group
}

Objective: To determine the health-related quality of life at 4 years of age in children who had undergone cardiac surgery for congenital heart disease in early infancy.

\begin{abstract}
Methods: A prospective cohort study of infants undergoing cardiac surgery at 6 weeks of age or younger from July 2000 to June 2005 at the Stollery Children's Hospital. The quality of life was assessed using the Pediatric Quality of Life Inventory, version 4.0, generic core scales, and compared with normative values for the same age. The association between the perioperative variables and health-related quality of life was explored.
\end{abstract}

Results: A total of 242 infants underwent complex heart surgery during the study period. Of the 166 eligible survivors, 130 were included. No significant differences were present between the children with single ventricle versus biventricular repairs, except for lower physical health summary scores in the single ventricle patients $(P=.007)$. Compared with the normative data, the children with biventricular repair had lower total Pediatric Quality of Life Inventory, version 4.0, scores $(P=.001)$ and psychosocial health summary scores $(P<.001)$. The children with single ventricle repair also had lower physical health summary scores $(P=.003)$. Older age at surgery and markers of postoperative low cardiac output syndrome were associated with worse health-related quality of life, and greater socioeconomic status was associated with better quality of life.

Conclusions: At 4 years of age, health-related quality of life was significantly lower in children who had undergone surgery for congenital heart disease in early infancy. An association was found between age at surgery and postoperative low cardiac output and socioeconomic status and quality of life. (J Thorac Cardiovasc Surg 2013;145:482-8)

Supplemental material is available online.

Improved perioperative care for children with complex congenital heart disease (CHD) has led to decreased mortality. Increasing attention is now being given to the long-term outcomes for children after cardiac surgery. The long-term outcomes include neurodevelopment, social performance,

From the Department of Pediatrics, ${ }^{\text {a }}$ University of Alberta, Edmonton, Alberta, Canada; Pediatric Rehabilitation Outcomes Evaluation and Research Unit, ${ }^{\mathrm{b}}$ Glenrose Rehabilitation Hospital, Edmonton, Alberta, Canada; University of Alberta School of Public Health, ${ }^{\mathrm{c}}$ Edmonton, Alberta, Canada; University of Calgary Faculty of Social Work, ${ }^{\mathrm{d}}$ Calgary, Alberta, Canada; and Department of Surgery, ${ }^{\mathrm{e}}$ University of Alberta, Edmonton, Alberta, Canada.

Financial support was provided by the Registry and Follow-up of Complex Pediatric Therapies Project, Alberta Health and Wellness.

Disclosures: Authors have nothing to disclose with regard to commercial support.

The Western Canadian Complex Pediatric Therapies Follow-up Group is as follows:

D. Moddemann, Winnipeg, Manitoba; P. Blakley, Saskatoon, Saskatchewan; R. S.

Sauve, Calgary, Alberta; J. Bodani Regina, Saskatchewan.

Received for publication Nov 25, 2011; revisions received March 9, 2012; accepted for publication March 19, 2012; available ahead of print April 16, 2012.

Address for reprints: Gonzalo Garcia Guerra, MD, Department of Pediatrics, 3A3.07

Stollery Children's Hospital, 8440-112 St, Edmonton, AB T6G 2B7, Canada

(E-mail: Gonzalo.Guerra@albertahealthservices.ca).

$0022-5223 / \$ 36.00$

Copyright (c) 2013 by The American Association for Thoracic Surgery

doi:10.1016/j.jtcvs.2012.03.050 and health-related quality of life (HRQL). HRQL is a multidimensional construct that includes physical, mental, and social well-being dimensions, not merely the absence of disease. The published data have consistently suggested that the clinical condition or disease severity is not necessarily associated with the perception of quality of life. ${ }^{1}$ HRQL refers to a person's subjective, emotional evaluation and reaction to their health condition. ${ }^{2}$ The assessment of HRQL in patients with CHD is challenging because of the variability in age, neurodevelopmental capabilities, and diagnoses. Accordingly, an examination is needed of the HRQL variability in children who have undergone early complex cardiac surgery.

To address this knowledge gap, a study was undertaken to assess HRQL in children treated in infancy for CHD. We hypothesized that children who had undergone cardiac surgery for CHD in early life would have lower HRQL scores compared with population-normative data. We also hypothesized that those perioperative variables previously known to be associated with neurodevelopmental outcomes for these children would also be associated with their HRQL at 4 years of age.

\section{METHODS}

The present study was a part of a prospective interprovincial inception cohort outcomes follow-up project conducted in 4 provinces in Western Canada. The infants were identified at the time of complex cardiac surgery 


\section{Abbreviations and Acronyms \\ $\mathrm{CPB}=$ cardiopulmonary bypass \\ $\mathrm{CHD}=$ congenital heart disease \\ $\mathrm{HRQL}=$ health-related quality of life}

and were followed up prospectively. In the present study, we included all infants aged 6 weeks or younger who had undergone complex cardiac surgery for CHD, including cardiopulmonary bypass (CPB), at the Stollery Children's Hospital from July 2000 to June 2005. We excluded those patients with chromosomal abnormalities, those who had received a heart transplant, and those needed extracorporeal life support. Karyotype and DNA analysis is routinely performed in all these patients. No specific protocol was used for anesthetic management in the operating room. In general, maintenance anesthesia during $\mathrm{CPB}$ was with high-dose opioid using fentanyl or sufentanil and supplemented by a volatile anesthetic, including sevoflurane, desflurane, or isoflurane, at the anesthetist's discretion. During the study period, the infants underwent surgery using standard single or bicaval venous cannulation, depending on the anatomy, with the CPB circuit primed with blood, targeting a hematocrit of 0.30 . Moderate hypothermia $\left(25^{\circ}-28^{\circ} \mathrm{C}\right)$ was used for patients not requiring circulatory arrest, and the pump flow was 100 to $150 \mathrm{~mL} / \mathrm{kg} / \mathrm{min}$. For patients requiring significant periods of deep hypothermic circulatory arrest, generally those involving aortic arch reconstruction or total anomalous pulmonary venous connection, a target core temperature of $18^{\circ}$ to $20^{\circ} \mathrm{C}$ was achieved using a modified $\mathrm{pH}$-stat strategy and topical cooling of the head. Target arterial partial pressure of carbon dioxide was 50 to $60 \mathrm{~mm}$ $\mathrm{Hg}$ at $20^{\circ} \mathrm{C}$, uncorrected for temperature. Myocardial protection was provided by dilute cold blood cardioplegia (1:4 blood/cardioplegia solution), usually repeated at 20- to 30-minute intervals, depending on the anatomy. During the latter part of this era, regional low flow perfusion techniques were introduced to reduce the period of deep hypothermic circulatory arrest for patients requiring arch reconstruction. This involved sewing a graft on to the innominate artery, snaring the origins of the neck vessels, and flowing at 25 to $50 \mathrm{~mL} / \mathrm{kg} / \mathrm{min}$ at $20^{\circ} \mathrm{C}$.

The previously agreed on demographic, preoperative, intraoperative, and postoperative variables were collected prospectively. ${ }^{3}$ Long-term follow-up was discussed with the parents or guardians once survival was probable. With their written consent for participation, contact was made with their respective follow-up clinics at the tertiary site of origin. The follow-up study and database received institutional health research ethics board approval.

The history and physical measurements were obtained as previously described. ${ }^{3}$ The family socioeconomic status was determined using the Blishen Index. ${ }^{4}$ Maternal education was indicated by years of schooling. The outcomes assessments were completed at 4 years of age at the tertiary site of origin. Single ventricle physiology was defined as an arterial oxygen saturation persistently less than $90 \%$ owing to the mixing of poorly oxygenated with oxygenated blood secondary to a right-to-left intracardiac or extracardiac shunt. The baseline characteristics of the patients assessed at 4 years of age were compared with those lost to follow-up (data not shown).

\section{HRQL Instrument}

The HRQL was assessed using the Pediatric Quality of Life Inventory, version 4.0 (PedsQL 4.0), generic core scales completed by the children's parents at the 4-year follow-up point. This instrument invites parents to report on the quality of life of their child during the past 30 days as seen from the perspective of their child. The PedsQL 4.0 generic core scale is a 23item tool that encompasses the following domains: physical functioning (8 items), emotional functioning (5 items), social functioning (5 items), and school functioning ( 5 items). The items are reverse scored and linearly transformed to a 0 to 100 scale; higher scores indicate better HRQL. The physical health summary score ( 8 items) is the same as the physical functioning subscale. To create a psychosocial health summary score, the mean was computed as the sum of the items divided by the number of items in the emotional, social, and school functioning scales. In terms of effect, the PedsQL 4.0 is a well-known instrument used to measure HRQL in children; its validity and reliability have been demonstrated and are acceptable for group comparisons. ${ }^{5,6}$

\section{Statistical Analysis}

The categorical variables are described as frequencies and continuous variables as the mean and standard deviation. We prespecified 2 patient subgroups, those with biventricular and those with single ventricle surgical repairs. The total PedsQL 4.0 scores from patients with single ventricle and biventricular repairs were compared with published normative values for the same age. ${ }^{6}$ We also compared the results of patients with single ventricle and biventricular repairs within our cohort.

We used the $t$-test for independent samples with Bonferroni correction to compare the results across 2 groups. Multiple linear regression analysis was performed to identify those perioperative variables (Table E1) independently associated with the PedsQL 4.0 and each summary score and consisted of variables found significant at $P \leq .10$ in the univariate analysis, after adjusting for multicolinearity. The results are presented as effect sizes and $95 \%$ confidence intervals and 2 -sided $P$ values. We considered statistically significant those variables with $P<.05$ on multivariate analysis. Statistical analyses were performed using SAS, version 9.1 (SAS Institute, Cary, NC).

\section{RESULTS}

\section{Description of Cohort}

A total of 242 infants underwent complex heart surgery during the study period. Of the 242 children, 28 were excluded: 17 had a chromosomal abnormality, 7 required extracorporeal life support, 2 had received a heart transplant, and 2 had required extracorporeal life support and received a heart transplant. Also, 48 children died before the 4 -year follow-up point. Of the 166 eligible surviving patients, 26 parents did not receive the PedsQL 4.0 forms, 2 refused to complete the forms, 1 patient was too ill to undergo follow-up, and 7 families were lost to follow-up, leaving 130 patients for analysis. Of the 130 children, 100 had undergone biventricular repair and 30 single ventricle repairs. The CHD diagnoses of the cohort are listed in Table E2.

\section{Univariate Comparisons}

At the 4-year follow-up point, no significant difference was seen between the total PedsQL 4.0 scores $(P=.057)$ in children with single ventricle repairs and those with biventricular repairs. The only score that was significantly different was in physical functioning, for which children who had a single ventricle repair during infancy had a lower mean score (82.2 vs $76.9, P=.007)$. No significant difference was seen between the children with single ventricle versus biventricular repairs in the psychosocial health summary, emotional functioning, social functioning, and school functioning scores (Table E3). Post hoc, we explored whether the predominance of patients with transposition of the great arteries was responsible for the better HRQL 
TABLE 1. Mean Pediatric Quality of Life Inventory, version 4.0, scores in normative data and children with biventricular and single ventricle repair

\begin{tabular}{|c|c|c|c|c|c|c|c|}
\hline Domains & $\begin{array}{l}\text { Normative data } \\
\quad(\mathbf{n}=\mathbf{9 0 7})\end{array}$ & $\begin{array}{l}\text { Biventricular repair } \\
\quad(\mathbf{n}=100)\end{array}$ & $\begin{array}{c}\text { Effect size } \\
(95 \% \mathrm{CI})\end{array}$ & $P$ value & $\begin{array}{l}\text { Single ventricle repair } \\
\qquad(\mathbf{n}=\mathbf{3 0})\end{array}$ & $\begin{array}{c}\text { Effect size } \\
(95 \% \mathrm{CI})\end{array}$ & $P$ value \\
\hline Physical functioning & $89.2 \pm 17.0$ & $89.3 \pm 12.2$ & $-0.1(-3.5,3.3)$ & .954 & $76.9 \pm 20.2$ & $12.3(6.0,18.5)$ & $.0001 *$ \\
\hline Emotional functioning & $84.7 \pm 13.9$ & $76.7 \pm 17.4$ & $8(5.0,10.9)$ & $<.0001^{*}$ & $78.9 \pm 14.9$ & $5.8(0.7,10.8)$ & .025 \\
\hline Social functioning & $87.7 \pm 16.6$ & $82.8 \pm 17.6$ & $4.9(1.4,8.3)$ & $.005^{*}$ & $79.7 \pm 17.4$ & $8(1.9,14.0)$ & .009 \\
\hline School functioning & $86.1 \pm 16.6$ & $76.1 \pm 20.5$ & $10(6.5,13.5)$ & $<.0001^{*}$ & $70.8 \pm 24.1$ & $15.3(9.1,21.4)$ & $<.0001 *$ \\
\hline Physical health summary & $89.2 \pm 17.0$ & $89.3 \pm 12.2$ & $-0.1(-3.5,3.3)$ & .954 & $76.9 \pm 20.2$ & $12.3(6.1,18.5)$ & $.0001 *$ \\
\hline Psychosocial health summary & $86.1 \pm 12.3$ & $77.7 \pm 16.4$ & $8.4(5.7,11.0)$ & $<.0001 *$ & $76.6 \pm 16.6$ & $9.5(4.9,14.0)$ & $<.0001 *$ \\
\hline Total & $87.3 \pm 12.6$ & $82.2 \pm 12.8$ & $5.1(2.5,7.7)$ & $.0001 *$ & $76.9 \pm 17.1$ & $10.4(5.7,15.0)$ & $.0001 *$ \\
\hline
\end{tabular}

Data presented as mean \pm standard deviation, unless otherwise noted. $C I$, Confidence interval. *Significant after Bonferroni correction $(P<.007)$.

in the biventricular patients. No statistically significant difference was found in the total PedsQL, physical functioning, or psychosocial health summary between the transposition of the great arteries and other biventricular patients (data not shown). In addition, no significant association was found between the Risk Adjusted classification for Congenital Heart Surgery score and any of the HRQL scores (data not shown).

Compared with the normative data, children with biventricular repair had significantly lower mean PedsQL 4.0 scores ( 82.2 vs $87.3, P=.0001$ ), including lower psychosocial health summary (77.7 vs $86.1, P<.0001$ ), emotional functioning (76.7 vs $84.7, P<.0001$ ), social functioning (82.8 vs $87.7, P=.005)$, and school functioning (76.1 vs $86.1, P<.0001)$ scores. No significant difference was seen in the physical health summary mean score between children with biventricular repair and the population norms (Table 1).

Children with single ventricle repair during infancy, compared with normative data, had significantly lower scores in all the domains except for emotional functioning (78.9 vs $84.7, P=.025)$ and social functioning (79.7 vs 87.7, $P=.009)$. The scores for the children with single ventricle repair compared with the population norms were as follows: total PedsQL 4.0, 76.9 versus $87.3(P<.0001)$; psychosocial health summary, 76.6 versus $86.1(P \leq .0001)$; physical health summary, 76.9 versus $89.2(P=.0001)$; and school functioning, 70.8 versus $86.1(P \leq .0001$; Table 1$)$.

\section{Multivariate Comparisons}

Multivariate linear regression analysis was performed to explore the association between each of the PedsQL 4.0 scores and perioperative variables. Older age at surgery and greater lactate levels in the late postoperative phase were associated with lower total PedsQL 4.0 (Table 2), physical summary, and psychosocial summary scores at 4 years of age (Tables 3 and 4). A significant interaction effect of age at surgery was found for the total PedsQL 4.0 and physical summary scores. The effect of age at surgery on the total PedsQL 4.0 score was more pronounced for children with single ventricle repair than for children with biventricular repair. In addition, the relationship between age and total PedsQL 4.0 score might have an inflection point at 10 days of age (Figure E1). For the physical summary scores, the association with age at surgery was only significant for those children who underwent single ventricle repair. A higher socioeconomic index was significantly associated with greater physical summary scores at 4 years of age (Table 3).

TABLE 2. Univariate and multivariable linear regression analysis results for total Pediatric Quality of Life Inventory, version 4.0, score in 130 infants having cardiac surgery

\begin{tabular}{|c|c|c|c|c|}
\hline \multirow[b]{2}{*}{ Variable } & \multicolumn{2}{|c|}{ Univariate } & \multicolumn{2}{|c|}{ Multivariate } \\
\hline & Effect size $(95 \%$ CI) & $P$ value & Effect size $(95 \%$ CI $)$ & $P$ value \\
\hline Preoperative ventilation (d) & $-0.78(-1.17,-0.38)$ & .000 & & \\
\hline Age at surgery (d) & $-0.42(-0.64,-0.20)$ & .000 & $\begin{array}{l}-1.17(-1.69,-0.66)^{*} \\
-0.30(-0.53,-0.08) \dagger\end{array}$ & $\begin{array}{l}.000 \\
.008\end{array}$ \\
\hline Lowest $\mathrm{PaO}_{2}$ days $2-5$ postoperatively & $0.20(0.06,0.35)$ & .007 & & \\
\hline Highest lactate day $6+$ postoperatively & $-2.74(-5.17,-0.31)$ & .027 & $-2.73(-4.97,-0.50)$ & .017 \\
\hline Socioeconomic index & $0.20(0.02,0.38)$ & .027 & $0.16(-0.01,0.32)$ & .058 \\
\hline Highest plasma lactate preoperatively $(\mathrm{mmol} / \mathrm{L})$ & $-0.56(-1.08,-0.04)$ & .034 & & \\
\hline Single ventricle repair & $-5.38(-10.97,0.20)$ & .059 & & \\
\hline Lowest $\mathrm{PaO}_{2}$ day $6+$ postoperatively & $0.11(-0.01,0.24)$ & .068 & & \\
\hline CPB time (min) & $-0.05(-0.10,0.00)$ & .070 & & \\
\hline
\end{tabular}

$C I$, Confidence interval; $\mathrm{PaO}$, arterial partial pressure of oxygen; $\mathrm{CPB}$, cardiopulmonary bypass. ${ }^{*}$ Children with single ventricle physiology. $\dagger$ Children with biventricluar physiology. 
TABLE 3. Univariate and multivariate linear regression analysis results for physical summary score

\begin{tabular}{|c|c|c|c|c|}
\hline & \multicolumn{2}{|c|}{ Univariate } & \multicolumn{2}{|c|}{ Multivariate } \\
\hline & Effect size $(95 \%$ CI $)$ & $P$ value & Effect size $(95 \%$ CI $)$ & $P$ value \\
\hline Single ventricle repair & $-12.02(-17.88,-6.16)$ & .000 & & \\
\hline Lowest $\mathrm{PaO}_{2}$ days $2-5$ postoperative & $0.31(0.16,0.47)$ & .000 & & \\
\hline Preoperative mechanical ventilation (d) & $-0.86(-1.29,-0.43)$ & .000 & & \\
\hline Lowest $\mathrm{PaO}_{2}$ day $6+$ postoperatively $(\mathrm{mm} \mathrm{Hg})$ & $0.20(0.06,0.33)$ & .004 & & \\
\hline Age at surgery (d) & $-0.31(-0.56,-0.06)$ & .015 & $\begin{array}{l}-1.16(-1.72,-0.60)^{*} \\
-0.20(-0.44,0.04) \dagger\end{array}$ & $\begin{array}{c}<.0001 \\
.098\end{array}$ \\
\hline Socioeconomic index & $0.24(0.05,0.44)$ & .016 & $0.21(0.04,0.39)$ & .019 \\
\hline Highest lactate day $6+$ postoperatively & $-3.26(-5.94,-0.59)$ & .017 & $-2.53(-4.95,-0.12)$ & .04 \\
\hline PICU length of stay (d) & $-0.15(-0.28,-0.02)$ & .022 & & \\
\hline Lowest $\mathrm{PaO}_{2}$ day 1 postoperatively & $0.14(0.02,0.25)$ & .023 & & \\
\hline Inotrope score day $6+$ postoperatively & $-0.38(-0.75,-0.02)$ & .040 & & \\
\hline Inotrope score day 1 postoperatively & $-0.27(-0.54,-0.01)$ & .044 & & \\
\hline Inotrope score days $2-5$ postoperatively & $-0.23(-0.49,0.02)$ & .076 & & \\
\hline Highest lactate day 1 postoperatively $(\mathrm{mmol} / \mathrm{L})$ & $-0.73(-1.55,0.09)$ & .081 & & \\
\hline
\end{tabular}

$\mathrm{CI}$, Confidence interval; $\mathrm{PaO} 2$, arterial partial pressure of oxygen; $\mathrm{PICU}$, pediatric intensive care unit. *Children with single ventricle physiology. $\dagger$ Children with biventricular physiology.

A negative association was found between the greatest inotrope score preoperatively and the emotional functioning scores (Table E3). Greater lactate levels preoperatively, older age at surgery, and greater inotrope scores from day 6 postoperatively were associated with lower social functioning scores (Table E4). Patient age at surgery and the greatest lactate level on postoperative days 2 to 5 were associated with lower school functioning scores. A greater socioeconomic index was found to be associated with higher school functioning scores (Table E5).

\section{DISCUSSION}

In the present prospective cohort of 130 children who underwent complex heart surgery for CHD during early infancy, HRQL was evaluated at 4 years of age using the PedsQL 4.0. Children with biventricular repairs had significantly lower total PedsQL 4.0 scores than the normative population, reflecting overall worse HRQL. These children had significantly lower scores in all dimensions (emotional functioning, school functioning, social functioning, and psychosocial health summary scores) except for physical functioning, compared with population norms. Children with single ventricle repair had significantly lower total PedsQL 4.0 and physical and psychosocial dimensions of HRQL than the normative population. Compared with the children with biventricular repair, patients with single ventricle repair showed similar HRQL, except for lower physical functioning.

The increased survival after surgical repair of CHD has reduced mortality. Outcome studies of this group of patients have evolved from simple physical outcomes to more comprehensive outcomes such as neurodevelopment function and HRQL., ${ }^{4,8}$ Having a greater understanding of the multidimensional effects of these surgical procedures relative to the long-term experience of these children with CHD and their families is important to optimizing healthcare interventions and improving long-term outcomes. However, only a small number of studies of HRQL in children and adolescents after complex cardiac surgery for CHD have been published to date.

A recent systematic review of HRQL after childhood surgery for CHD found only 12 studies published from 1990 to $2008 .^{8}$ Previous studies have been performed in different patient populations, have included different reference

TABLE 4. Univariate and multivariate linear regression analysis results for psychosocial summary score

\begin{tabular}{|c|c|c|c|c|}
\hline & \multicolumn{2}{|c|}{ Univariate } & \multicolumn{2}{|c|}{ Multivariate } \\
\hline & Effect size $(95 \%$ CI $)$ & $P$ value & Effect size $(95 \%$ CI $)$ & $P$ value \\
\hline Age at surgery (d) & $-0.37(-0.64,-0.11)$ & .006 & $-0.37(-0.63,-0.10)$ & .007 \\
\hline Highest lactate preoperatively $(\mathrm{mmol} / \mathrm{L})$ & $-0.69(-1.30,-0.08)$ & .027 & & \\
\hline Highest inotrope score preoperatively & $-0.18(-0.36,-0.01)$ & .040 & & \\
\hline Preoperative mechanical ventilation (d) & $-0.50(-0.98,-0.02)$ & .041 & & \\
\hline Socioeconomic index & $0.21(-0.01,0.42)$ & .059 & $0.16(-0.05,0.37)$ & .127 \\
\hline Highest lactate day $6+$ postoperatively & $-2.74(-5.62,0.15)$ & .063 & $-3.00(-5.81,-0.20)$ & .036 \\
\hline
\end{tabular}

CI, Confidence interval. 
populations, and had conflicting results. The heterogeneity of the HRQL assessment methods and varying follow-up intervals precluded a formal meta-analysis of the topic.

Our results for children undergoing biventricular repair have confirmed the findings from previous studies in which children with CHD had worse HRQL than that of healthy controls. $^{1,2,9-12}$ These studies, despite showing similar results, were different from ours in several respects. Berkes and colleagues ${ }^{11}$ included surgical and nonsurgical patients with heart disease followed up in a cardiology clinic; the patients also had a wide variety of ages and diagnoses. Three of the studies included only surgical patients with CHD; however, the age at surgical repair and HRQL assessment varied. ${ }^{2,9,12}$ Mussatto and Tweddell ${ }^{1}$ studied a cohort of children similar to our patients, who underwent surgical repair early in infancy. However, the age at assessment ranged from 2 to 18 years old. ${ }^{1}$ Our study included only patients who had undergone surgery early in infancy and the HRQL assessment was performed at the same age in the entire cohort. This provides a better perspective for the comparison between patients and healthy controls of the same age. This will also allow us to follow them over time and compare their HRQL at different stages of their lives. Many studies have shown that HRQL changes over time; children at older ages might learn how to cope with their health issues and develop a different perspective on how their disease affects their quality of life. ${ }^{1,2}$

In contrast to our results, some studies have reported that children with CHD have the same or better HRQL scores than those of population norms. ${ }^{13-19}$ However, these studies had variable results, with 4 of them reporting HRQL scores comparable to normative samples, another showing normal results according to a cutoff point, and 1 study of children with transposition of the great arteries reporting better than normative HRQL. The latter study included only pediatric reports and was focused on health status more than HRQL. ${ }^{13}$

Our results for children undergoing single ventricle surgical repair are consistent with those from previous studies. Marino and colleagues ${ }^{20}$ conducted a study using the disease-specific Pediatric Cardiac Quality of Life Inventory and found that patients with single ventricle repair had lower Pediatric Cardiac Quality of Life Inventory scores than children with biventricular repair. ${ }^{20}$ Another study of patients after Fontan repairs showed lower health status score than the normative population. ${ }^{9}$ A more recent study also compared the HRQL of patients with simple congenital heart lesions versus complex CHD and found a significant difference with lower HRQL scores in children with more complex defects. ${ }^{11}$

In contrast, Ekman-Joelsson and colleagues ${ }^{17}$ conducted a study on the HRQL of children after surgical repair of pulmonary atresia with intact ventricular septum and found no difference between those with single ventricle repair and biventricular repairs. Another study found no significant differences in patients with single ventricle versus biventricular repair, although they noted a trend toward lower physical and emotional functioning in the single ventricle group. ${ }^{18}$ These studies differ from our study in that they reported the HRQL of children with a wide range of ages from 1 to 20 years.

Studies exploring the association between perioperative factors and HRQL in children after surgical repair of CHD are scarce. Moreover, the results of these studies have not been consistent. Although some have found gender, CPB time, deep hypothermic circulatory arrest, socioeconomic status, and maternal education to be associated with HRQL, others have not confirmed these risk factors. ${ }^{12,13,16,19,21-23}$ We found socioeconomic status was associated with physical summary and school functioning scores. We also found novel associations. A negative association was seen between age at surgery and the available markers, indicating postoperative low cardiac output syndrome (lactate and inotrope score) and HRQL at 4 years of age. This is the first study describing an association between age at surgery and signs of low cardiac output in the postoperative period and HRQL later in life. The association between age at surgery and lower HRQL seems to be more significant for those infants undergoing single ventricle repair and was consistent for most of the dimensions of HRQL. The ideal age for surgical repair in the neonatal period remains unknown. Although waiting for hemodynamic stability and decreased pulmonary vascular resistance seems reasonable, waiting too long might adversely affect the long-term outcomes. The scatterplot of the association between age at surgery and total PedsQL 4.0 score might have an inflection point at 10 days of age, with worse HRQL in those children undergoing surgical repair after day 10. This should be interpreted with caution, given the limitations of the inception cohort design and possible unaccounted for confounding variables associated with later surgery. The proportion of the total PedsQL 4.0 explained by these perioperative variables was $25 \%\left(\mathrm{r}^{2}=.25\right)$, indicating that other perioperative variables and/or experiences after surgery have a significant role in determining HRQL.

These findings, relative to the sparse and disparate data, demonstrate the need for additional research in this substantive area. The homogeneity of the findings appears to invite increased exploration both theoretically and empirically with the aim of understanding the mechanisms and determinants of HRQL in this population and across treatments. Achieving such an aim of greater understanding has the potential to yield important implications for clinical practice, including clarity for treatment decision-making and the determination of potential targeted supports and services to differentially meet the needs of these children and their families. 
Most of the studies published to date included cohorts with a wide age range or were composed predominately of adolescents and young adults. ${ }^{1,2,9,11,13-15,17,19,20,22,24,25}$ Our study had the strength of being an inception cohort of patients, all of whom underwent cardiac surgery very early in infancy, were assessed at the same age (4 years old), and were compared with a normative population of the same age. Our study included patients with single ventricle repair, allowing comparison with children with biventricular repair and the normative population. In addition, few studies have considered the perioperative variables and their association with HRQL. ${ }^{12,13,16,19,23}$ This is the first study to show an association between age at surgery and HRQL.

The study had some limitations. The HRQL was evaluated using the parents' perspective. Several studies have shown significant variability between the parents' and children's reports of HRQL. ${ }^{2,25}$ At the time of follow-up, these children were 4 years old, an age when only proxy reports can be obtained. Reassessment of the same cohort in the future will allow a comparison between the child's and parent's scores. Also, $22 \%$ of the survivors in this cohort were not evaluated at 4 years, which could have caused a selection bias. No significant differences were seen in the baseline characteristics of these children and those being assessed. Also, the Hawthorne effect could not be excluded as a source of bias in this type of study. We did not have a control group of children with CHD who did not undergo surgery; however, we believe that the comparison with a normative sample is important information when discussing the prognosis with parents. We did not have the socioeconomic status of the normative population used by Varni and colleagues ${ }^{6}$ to compare with our cohort. Nevertheless, the socioeconomic status of our cohort was not significantly different from that reported for the Canadian population. ${ }^{4,5}$ The lack of a significant difference in HRQL in the prespecified subgroup analysis comparing children with single ventricle and biventricular repair (except for the physical functioning summary score) should be interpreted with caution owing to the lack of statistical power. The comparison of HRQL between patients with single ventricle and biventricular repair should be studied in a larger cohort of patients.

\section{CONCLUSIONS}

Psychosocial outcomes might contribute to a better understanding of the overall long-term outcomes of these patients and families and describe how the survivors perform in society and experience daily living. The findings of our study invite greater consideration of the perioperative risk factors and potential resources fostering HRQL in children with CHD. Additional research examining the key elements determining and contributing to outcomes for these children is still needed. The strategies for the care of children with
CHD should take into account not only the medical aspects of the disease and its treatment, but also the factors affecting the external, interpersonal, and personal spheres of these children's lives.

\section{References}

1. Mussatto K, Tweddell J. Quality of life following surgery for congenital cardiac malformations in neonates and infants. Cardiol Young. 2005;15(Suppl 1): 174-8.

2. Spijkerboer AW, Utens EMWJ, De Koning WB. Health-related quality of life in children and adolescents after invasive treatment for congenital heart disease. Qual Life Res. 2006;15:663-73.

3. Robertson CMT, Sauve RS, Joffe AR, Alton GY, Moddemann DM, Blakely PM, et al. The registry and follow-up of complex pediatric therapies program of western Canada: a mechanism for service, audit, and research after life-saving therapies for young children. Cardiol Res Pract. 2011;21:932-41.

4. Blishen BR. The 1981 socioeconomic index for occupations in Canada. Can Rev Soc Anthes. 1987;24:465-88.

5. Varni JW, Limbers CA, Burwinkle TM. Parent proxy-report of their children's health-related quality of life: an analysis of 13,878 parents' reliability and validity across age subgroups using the PedsQL 4.0 generic core scales. Health Qual Life Outcomes. 2007;5:2

6. Varni JW, Seid M, Kurtin PS. PedsQL 4.0: reliability and validity of the Pediatric Quality of Life Inventory version 4.0 generic core scales in healthy and patient populations. Med Care. 2001;39:800-12.

7. Alton GY, Rempel GR, Robertson CMT, Newburn-Cook CV, Norris CM. Functional outcomes after neonatal open heart surgery: comparison of the survivors of the Norwood stage procedure and the arterial switch operation. Cardiol Young. 2010;20:668-75

8. Latal B, Helfricht S, Fischer JE, Bauersfeld U, Landolt MA. Psychological adjustment and quality of life in children and adolescents following open-heart surgery for congenital heart disease: a systematic review. BMC Pediatr. 2009; 9:6

9. McCrindle BW, Williams RV, Mitchell PD, Hsu DT, Paridon SM, Atz AM, et al Relationship of patients and medical characteristics to health status in children and adolescents after Fontan procedure. Circulation. 2006;113:1123-9.

10. Uzark K, Jones K, Burwinkle TM, Varni JW. The pediatric quality of life inventory in children with heart disease. Prog Pediatr Cardiol. 2003;18:141-8.

11. Berkes A, Varni JW, Pataki I, Kardos L, Kemény C, Mogyorósy G. Measuring health-related quality of life in Hungarian children attending a cardiology clinic with the Pediatric Quality of Life Inventory. Eur J Pediatr. 2010;169:333-47.

12. Landolt MA, Valsangiacomo Beuchel ER, Latal B. Health-related quality of life in children and adolescents after open-heart surgery. J Pediatr. 2008;152:349-55.

13. Culbert EL, Ashburn DA, Cullen-Dean G, Joseph JA, Williams WG Blackstone EH, et al. Quality of life of children after repair of transposition of the great arteries. Circulation. 2003;108:857-62.

14. Meijboom F, Szatmari A, Deckers JW, Utens EM, Roelandt JR, Bos E, et al. Cardiac status and health-related quality of life in the long term after surgical repair of tetralogy of Fallot in infancy and childhood. J Thorac Cardiovasc Surg. 1995; 110:883-91

15. Møyen Laane K, Meberg A, Otterstad JE, Frøland G, Sørland S, Lindström B et al. Quality of life in children with congenital heart defects. Acta Paediatr. 1997;86:975-80.

16. Dunbar-Masterson C, Wypij D, Bellinger DC, Rappaport LA, Baker AL, Jonas RA, et al. General health status of children with d-transposition of the great arteries after arterial switch operation. Circulation. 2001;104(Suppl I):I-138-42.

17. Ekman-Joelsson BM, Berntsson L, Sunnergårdh J. Quality of life in children with pulmonary atresia and intact ventricular septum. Cardiol Young. 2004;14:615-21.

18. Brosig CL, Mussatto KA, Kuhn EM, Tweddell JS. Psychosocial outcomes for preschool children and families after surgery for complex congenital heart disease. Pediatr Cardiol. 2007;28:255-62.

19. Hovels-Gurich HH, Konrad K, Wiesner M, Minkenberg R, HerpertzDahlmann B, Messmer BJ, et al. Long term behavioral outcome after neonata arterial switch operation for transposition of the great arteries. Arch Dis Child. 2002;87:506-10.

20. Marino BS, Shera D, Wernovsky G, Tomlinson RS, Aquirre A, Gallagher M et al. The development of the pediatric cardiac quality of life inventory: a quality of life measure for children and adolescents with heart disease. Qual Life Res. 2008; 17:613-26. 
21. Williams DL, Gelijns AC, Moskowitz AJ, Weinberg AD, Nq JH, Crawford E, et al. Hypoplastic left heart syndrome: valuing the survival. J Thorac Cardiovasc Surg. 2000;119:720-31.

22. Larsen SH, McCrindle BW, Jacobsen EB, Johnsen SP, Emmertsen K, Hjordtdal VE. Functional health status in children following surgery for congenital heart disease: a population-based cohort study. Cardiol Young. 2010;20: 631-40.

23. Majnemer A, Limeropoulos C, Shevell M, Rohlicek C, Rosenblatt B, Tchervenkov $\mathrm{C}$. Health and well-being of children with congenital cardiac malformations, and their families, following open-heart surgery. Cardiol Young 2006;16:157-64.

24. Lambert LM, Minich LL, Newburger JW, Lu M, Pemberton VL, McGrath EA, et al. Parents- versus child-reported functional health status after the Fontan procedure. Pediatrics. 2009;124:e942-9.

25. Marino BS, Tomlinson RS, Drotar D, Claybone ES, Aquirre A, Ittenbach R, et al. Quality of life concerns differ among patients, parents and medical providers in children and adolescents with congenital and acquired heart disease. Pediatrics. 2009;123:e708-15. 


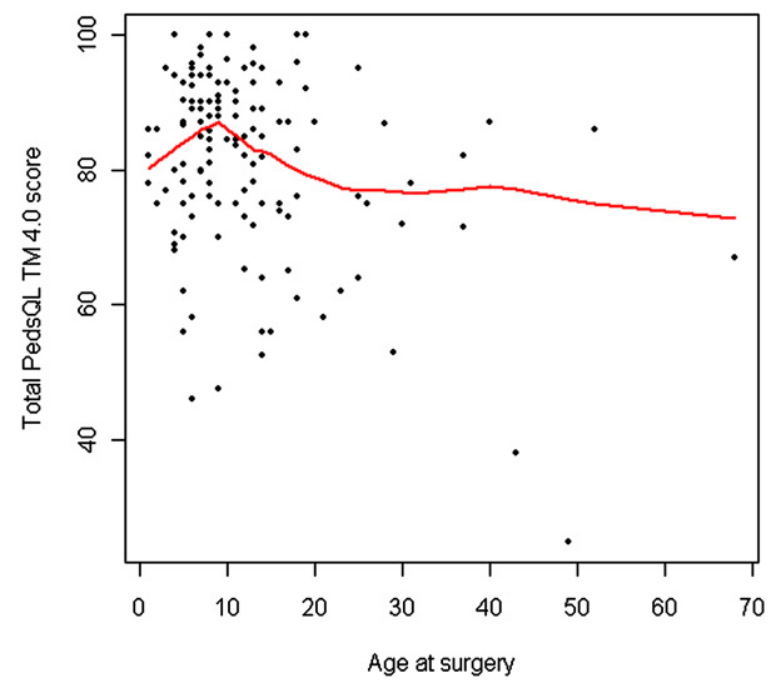

FIGURE E1. Scatterplot of total Pediatric Quality of Life Inventory, version 4.0, (PedsQL 4.0) score versus age at surgery in days.

TABLE E1. Potential predictor variables included in univariate regression analyses

\begin{tabular}{|c|c|}
\hline Variable & Mean \pm SD \\
\hline Socioeconomic index (Blishen) & $43.1 \pm 13.2$ \\
\hline Mother's years of school & $13.1 \pm 2.9$ \\
\hline Male gender (n) & $84.0 \pm 65$ \\
\hline Weight at surgery $(\mathrm{kg})$ & $3.3 \pm 0.6$ \\
\hline RACHS-1 & $4.0 \pm 1.1$ \\
\hline Age at treatment $(\mathrm{d})$ & $12.9 \pm 10.7$ \\
\hline Highest inotrope score preoperatively & $7.8 \pm 15.9$ \\
\hline Highest lactate preoperative (mmol/L) & $4.4 \pm 4.5$ \\
\hline Lowest $\mathrm{pH}$ preoperatively & $7.28 \pm 0.1$ \\
\hline Preoperative mechanical ventilation (d) & $5.7 \pm 5.8$ \\
\hline Lowest $\mathrm{PaO}_{2}$ preoperatively $(\mathrm{mm} \mathrm{Hg}$ ) & $37.5 \pm 16.4$ \\
\hline $\mathrm{CPB}$ time (min) & $116 \pm 44.6$ \\
\hline DHCA (n) & $85 \pm 65$ \\
\hline Highest inotrope score day 1 postoperatively & $13.9 \pm 9.9$ \\
\hline Highest lactate day 1 postoperatively $(\mathrm{mmol} / \mathrm{L})$ & $6.2 \pm 3.2$ \\
\hline Lowest $\mathrm{pH}$ day 1 postoperatively & $7.3 \pm 0.7$ \\
\hline Lowest $\mathrm{PaO}_{2}$ day 1 postoperatively $(\mathrm{mm} \mathrm{Hg}$ ) & $57.5 \pm 22$ \\
\hline Highest inotrope score days $2-5$ postoperatively & $13.5 \pm 10.1$ \\
\hline Highest lactate level days $2-5$ postoperatively (mmol/L) & $2.9 \pm 1.9$ \\
\hline Lowest $\mathrm{pH}$ days $2-5$ postoperatively & $7.34 \pm 0.06$ \\
\hline Lowest $\mathrm{PaO}_{2}$ days $2-5$ postoperatively $(\mathrm{mm} \mathrm{Hg}$ ) & $56.3 \pm 16.1$ \\
\hline Highest inotrope score day $6+$ postoperatively & $3.9 \pm 7.0$ \\
\hline Highest lactate day $6+$ postoperatively $(\mathrm{mmol} / \mathrm{L})$ & $1.2 \pm 1.0$ \\
\hline Lowest $\mathrm{pH}$ day $6+$ postoperatively & $7.35 \pm 0.1$ \\
\hline Lowest $\mathrm{PaO}_{2}$ day $6+$ postoperatively $(\mathrm{mm} \mathrm{Hg})$ & $53.9 \pm 19.5$ \\
\hline Postoperative mechanical ventilation (d) & $11.2 \pm 14.4$ \\
\hline PICU length of stay (d) & $18.6 \pm 19.9$ \\
\hline Hospital length of stay (d) & $31.8 \pm 31.1$ \\
\hline CPR (n) & $8 \pm 6.2$ \\
\hline
\end{tabular}

$S D$, Standard deviation; RACHS-1, Risk Adjustment for Congenital Heart Surgery; $C P B$, cardiopulmonary bypass; $D H C A$, deep hypothermic circulatory arrest; $\mathrm{PaO}_{2}$, arterial partial pressure of oxygen; $P I C U$, pediatric intensive care unit; $C P R$, cardiopulmonary resuscitation.

TABLE E2. Diagnoses of enrolled patients

\begin{tabular}{lc}
\hline Diagnosis & Patients (n) \\
\hline HLHS & $29(22)$ \\
TGA & $62(48)$ \\
TOF & $2(2)$ \\
AVSD & $1(1)$ \\
TA & $6(4)$ \\
TAPVD & $15(11)$ \\
AS & $1(1)$ \\
IAA & $11(8)$ \\
PAtr & $1(1)$ \\
TAtr & $1(1)$ \\
HAA & $1(1)$ \\
\hline Data in parentheses are percentages. HLHS, Hypoplastic left heart syndrome; TGA, \\
transposition of the great arteries; TOF, tetralogy of Fallot; AVSD, atrioventricular \\
septal defect; $T A$, truncus arteriosus; TAPVD, total anomalous pulmonary venous \\
drainage; $A S$, aortic stenosis; IAA, interrupted aortic arch; PAtr, pulmonary atresia; \\
TAtr, tricuspid atresia; $H A A$, hypoplastic aortic arch.
\end{tabular}


TABLE E3. Mean Pediatric Quality of Life Inventory, version 4.0, scores by type of repair

\begin{tabular}{|c|c|c|c|c|}
\hline Domain & Biventricular repair $(n=100)$ & Single ventricle repair $(n=30)$ & Effect size $(95 \%$ CI $)$ & $P$ value \\
\hline Physical functioning & $89.3 \pm 12.2$ & $76.9 \pm 20.2$ & $12.4(6.4,18.3)$ & $.0001 *$ \\
\hline Emotional functioning & $76.7 \pm 17.4$ & $78.9 \pm 14.9$ & $-2.2(-9.1,4.7)$ & .532 \\
\hline Social functioning & $82.8 \pm 17.6$ & $79.7 \pm 17.4$ & $3.1(-4.1,10.3)$ & .400 \\
\hline School functioning & $76.1 \pm 20.5$ & $70.8 \pm 24.1$ & $5.3(-3.5,14.1)$ & .239 \\
\hline Physical health summary & $89.3 \pm 12.2$ & $76.9 \pm 20.2$ & $12.4(6.4,18.3)$ & $.0001 *$ \\
\hline Psychosocial health summary & $77.7 \pm 16.4$ & $76.6 \pm 16.6$ & $1.1(-5.6,7.8)$ & .741 \\
\hline Total & $82.2 \pm 12.8$ & $76.9 \pm 17.1$ & $5.3(-0.4,11.02)$ & .069 \\
\hline
\end{tabular}

$C I$, Confidence interval. $* P$ values significant after Bonferroni correction $(P<.007)$.

TABLE E4. Univariate and multivariate linear regression analysis results for emotional functioning score

\begin{tabular}{|c|c|c|c|c|}
\hline \multirow[b]{2}{*}{ Variable } & \multicolumn{2}{|c|}{ Univariate } & \multicolumn{2}{|c|}{ Multivariate } \\
\hline & Effect size $(95 \% \mathrm{CI})$ & $P$ value & Effect size $(95 \%$ CI $)$ & $P$ value \\
\hline Highest inotrope score preoperatively & $-0.21(-0.38,-0.03)$ & .025 & $-2.67(-4.77,-0.57)$ & .013 \\
\hline Highest lactate preoperative (mmol/L) & $-0.68(-1.31,-0.06)$ & .032 & & \\
\hline Age at surgery $(d)$ & $-0.30(-0.57,-0.02)$ & .034 & $-0.25(-0.52,0.01)$ & .063 \\
\hline Lowest $\mathrm{PaO}_{2}$ preoperatively $(\mathrm{mm} \mathrm{Hg})$ & $0.17(-0.01,0.35)$ & .071 & & \\
\hline Preoperative mechanical ventilation (d) & $-0.43(-0.93,0.06)$ & .085 & & \\
\hline Socioeconomic index & $0.17(-0.05,0.39)$ & .124 & $0.14(-0.08,0.35)$ & 211 \\
\hline
\end{tabular}

$\mathrm{CI}$, Confidence interval; $\mathrm{PaO}_{2}$, arterial partial pressure of oxygen.

TABLE E5. Univariate and multivariate linear regression analysis results for social functioning score

\begin{tabular}{|c|c|c|c|c|}
\hline \multirow[b]{2}{*}{ Variable } & \multicolumn{2}{|c|}{ Univariate } & \multicolumn{2}{|c|}{ Multivariate } \\
\hline & Effect size $(95 \% \mathrm{CI})$ & $P$ value & Effect size $(95 \%$ CI $)$ & $P$ value \\
\hline Socioeconomic index & $0.47(-0.58,1.51)$ & .379 & $0.23(-0.76,1.22)$ & .649 \\
\hline Age at surgery (d) & $-0.44(-0.72,-0.16)$ & .002 & $-0.36(-0.65,-0.08)$ & .014 \\
\hline Highest lactate preoperatively (mmol/L) & $-1.00(-1.64,-0.35)$ & .003 & $-0.68(-1.34,-0.03)$ & .042 \\
\hline Highest inotrope score preoperatively & $-0.22(-0.41,-0.04)$ & .020 & & \\
\hline Highest lactate day $6+$ postoperatively & $-3.56(-6.64,-0.49)$ & .023 & $-0.42(-0.82,-0.01)$ & .045 \\
\hline Highest inotrope score day $6+$ postoperatively & $-0.47(-0.89,-0.05)$ & .030 & & \\
\hline Preoperative mechanical ventilation (d) & $-0.49(-1.01,0.03)$ & .063 & & \\
\hline $\mathrm{CPB}$ time (min) & $-0.06(-0.13,0.00)$ & .067 & & \\
\hline
\end{tabular}

$\overline{C I}$, Confidence interval; $C P B$, cardiopulmonary bypass.

TABLE E6. Univariate and multivariate linear regression analysis for school functioning score

\begin{tabular}{|c|c|c|c|c|}
\hline \multirow[b]{2}{*}{ Variable } & \multicolumn{2}{|c|}{ Univariate } & \multicolumn{2}{|c|}{ Multivariate } \\
\hline & Effect size $(95 \%$ CI $)$ & $P$ value & Effect size $(95 \%$ CI $)$ & $P$ value \\
\hline Socioeconomic index & $0.39(0.11,0.66)$ & .006 & $0.31(0.04,0.58)$ & .023 \\
\hline Highest lactate level day $6+$ postoperatively & $-4.96(-8.67,-1.26)$ & .009 & & \\
\hline Age at surgery (d) & $-0.44(-0.78,-0.09)$ & .014 & $-0.45(-0.79,-0.11)$ & .009 \\
\hline Highest lactate level days $2-5$ postoperatively $(\mathrm{mmol} / \mathrm{L})$ & $-2.15(-4.10,-0.20)$ & .031 & $-2.20(-4.10,-0.30)$ & .023 \\
\hline Mothers' education (yr) & $1.38(0.13,2.64)$ & .031 & & \\
\hline Highest inotrope score day $6+$ postoperatively & $-0.56(-1.07,-0.04)$ & .034 & & \\
\hline Preoperative mechanical ventilation (d) & $-0.64(-1.27,-0.01)$ & .048 & & \\
\hline Highest inotrope score days $2-5$ postoperatively & $-0.32(-0.68,0.04)$ & .084 & & \\
\hline
\end{tabular}

CI, Confidence interval. 